\title{
Inhibition of Lipopolysaccharide-Induced Expression of Fractalkine by Methylprednisolone via NF- K b in Human Renal Tubular Epithelial Cells
}

\section{YanWu You' ${ }^{1}$, YueQiu Qin², Xu Lin', FaFen Yang1, Jun Li ${ }^{3}$, Suren Sooranna ${ }^{4}$ and Liao Pinhu ${ }^{3 *}$}

${ }^{1}$ Department of Nephrology, Affiliated Hospital of Youjiang Medical University for Nationalities, Guangxi Zhuang Autonomous Region, China ${ }^{2}$ Department of Gastroenterology, Affiliated Hospital of Youjiang Medical University for Nationalities, Guangxi Zhuang Autonomous Region, China

${ }^{3}$ Department of Intensive Care Medicine, Affiliated Hospital of Youjiang Medical University for Nationalities, Guangxi Zhuang Autonomous Region, China ${ }^{4}$ Department of Surgery and Cancer, Imperial College London, Chelsea and Westminster Hospital, London

\section{Abstract}

Objective: to study the effect of the glucocorticoid, methylprednisolone (MP), in lipopolysaccharide (LPS)-induced fractalkine (FKN) expression in HK-2 cells and to determine the role of NF-KB in this signaling pathway.

Methods: HK-2 cells were stimulated by LPS to set up an in vitro inflammation model. The concentration of FKN in cell culture supernatant was measured by ELISA. FKN and p65 mRNA expression were detected by RT-PCR. FKN, p65 protein expression and the activity of the NF-KB were detected by immunofluorescence staining and western blotting. The effect of MP and SC-514 (a selective and reversible inhibitor of IKK beta) in FKN expression and NF-KB activation induced by LPS were evaluated.

Results: LPS induced FKN expression and secretion in HK-2 cells occurred in a time- and dose-dependent manner and correlated with the activation of NF-KB. MP was able to inhibit FKN expression and secretion as well as the NF-KB induced activation of LPS, whereas SC-514 abolished this effect.

Conclusions: MP inhibited FKN expression induced by LPS through the NF-kB pathway in human renal tubular epithelial cells in vitro. Use of HK-2 cells to study the renal inflammatory process will allow the further elucidation of the pathways involved in kidney disease.

Keywords: Human renal tubular epithelial cells; NF-кB; Fractalkine; Methylprednisolone; Inflammation

\section{Introduction}

Extensive studies have confirmed that inflammatory mechanisms play significant roles in the pathogenesis of kidney disease [1,2]. Fractalkine $(\mathrm{FKN})$ is a unique member of the chemokines $\mathrm{CX} 3 \mathrm{C}$ superfamily [3]. TNF- $\alpha$, IL-1 and IFN- $\gamma$ is known to induce the expression of FKN in endothelial cells [4]. FKN is involved in the acute inflammatory response [5] where it acts as an adhesion molecule mediating inflammatory lesions and participates in the occurrence and progression of a variety of renal diseases [6-8] and damage processes of renal cells [9-11], in particular, renal tubular epithelial cells $[12,13]$. The expression of FKN has been shown to be increased in renal diseases [14-16]. It is produced as a precursor protein in cells and transfers to the cell surface as a mature protein after glycosylation [16,17].

Lipopolysaccharide (LPS) is a proinflammatory factor which plays an important role in the regulation of endogenous expression of FKN in endotoxemia. LPS induces the expression of inflammation factors such as prostaglandin E2 and TNF- $\alpha$ in RAW264.7 cells. The expression of inflammatory factors and the activity of NF- $\kappa \mathrm{B}$ are blocked by rosemary, when used as a medicinal herb [18]. LPS also stimulates the activation of NF- $\mathrm{KB}$ in human renal tubular epithelial cells [19]. The expression of MCP-1 increases and the expression of surface active protein D (SP-D) are reduced after incubation of human renal tubular epithelial cells with LPS. In addition, the LPS-induced MCP-1 expression is reduced by over-expression of SP-D in transfected cells [20]. LPS induces the expression of endogenous FKN protein in human umbilical vein endothelial cells whereas alpha-lipoic acid inhibits LPSinduced expression of endogenous FKN [21]. These results confirm that LPS induces the inflammatory reaction and FKN expression.

The activity of NF- $\mathrm{B}$, which includes Rel A (p65), p50, p52, Rel $B$ and $c-$ Rel, can be induced by pathogenic microorganisms, tumor growth factors and inflammatory factors. Activated NF- $\kappa B$ transfers from the cytoplasm to the nucleus, and then binds to specific DNA promoter regions and encodes proteins that regulates cell adhesion, proliferation and apoptosis [22]. Microarray analysis of renal tubular epithelial cells (HK-2) show that NF- $\kappa$ B plays a major role in the network structure of normal cells and that aristolochic acid has an inhibitory effect on the NF- $\kappa \mathrm{B}$ activity [23]. Several studies have confirmed that the NF- $\kappa B$ signaling pathway is involved in the first step of inflammatory reaction induced by LPS [24]. TNF- $\alpha$, stimulates the expression of FKN in an NF- $\mathrm{KB}$ dependent and autocrine manner in arterial smooth muscle cells [25] and the NF- $\kappa B$ pathway has been shown to be associated with expression of FKN. The binding activity of NF- $\kappa B$ DNA has been correlated with the expression of FKN induced by LPS in rat endothelial cells and the NF- $\mathrm{KB}$ inhibitor, an adenovirusmediated mutant of IkappaB inhibits the expression of FKN, suggesting that LPS induces expression of FKN in NF- $\mathrm{kB}$ dependent manner [26].

The glucocorticoid, methylprednisolone (MP), is a clinically effective drug that is not only used for the treatment of inflammatory diseases, but also the preferred drug against inflammation in kidney disease. But the mechanism for the beneficial effect of MP in renal inflammatory disease has still to be elucidated. Glucocorticoids have an inhibitory effect on FKN by reducing NF- $\mathrm{kB}$ gene promoter recruitment in respiratory epithelial A549 cells [27].

There is a need to investigate the protective effect of MP on the expression of FKN and the NF- $\mathrm{KB}$ pathway in the renal inflammatory

${ }^{*}$ Corresponding author: Liao Pinhu, Department of Intensive Care Medicine Affiliated Hospital of Youjiang Medical University for Nationalities, No.18 Zhongshan Road II, Baise 533000, Guangxi Zhuang Autonomous Region, China Tel: 008615277695188; E-mail: liaopinhu@163.com

Received January 28, 2015; Accepted February 28, 2015; Published March 03 , 2015

Citation: You YW, Qin YQ, Lin X, Yang FF, Li J, et al. (2015) Inhibition of Lipopolysaccharide-Induced Expression of Fractalkine by Methylprednisolone via NF-Kb in Human Renal Tubular Epithelial Cells. J Pulm Respir Med 5: 249. doi:10.4172/2161-105X.1000249

Copyright: ( 2015 You YW, et al. This is an open-access article distributed under the terms of the Creative Commons Attribution License, which permits unrestricted use, distribution, and reproduction in any medium, provided the original author and source are credited. 
process. The present study focuses on the effect of MP on LPS-induced expression of FKN and activation of NF- $\mathrm{KB}$ signaling pathway in HK-2 cells, and compares the effects seen in the presence of the NF- $\kappa B$ inhibitor, SC-514.

\section{Materials and Methods}

\section{Cell culture and experimental protocol}

This is an in vitro study using HK-2 cells purchased from China Center for Type Culture Collection (CCTCC, GDC0136). Cells were cultured in our laboratory in DMEM (Gibco, Life Technologies, USA) supplemented with $10 \%$ fetal calf serum, $100 \mathrm{mU} / \mathrm{mL}$ penicillin and $100 \mathrm{mg} / \mathrm{mL}$ streptomycin in T75 in an atmosphere of $5 \% \mathrm{CO}_{2}$ and $95 \%$ air at $37^{\otimes} \mathrm{C}$. Cells from passages 1 to 5 were trypsinized with $0.25 \%$ trypsin containing $0.02 \%$ EDTA in phosphate buffered saline (PBS) and cultured in 6-well plates in $2 \mathrm{~mL}$ of DMEM. When cells were $85 \%$ to $95 \%$ confluent (days 3-4), old medium was removed and replaced with $1 \mathrm{~mL}$ of fresh medium supplemented with $1 \%$ fetal calf serum overnight. Cells were incubated with and without LPS $(100 \mathrm{ng} / \mathrm{ml}$; Sigma Chemical Co.), MP (10-8 M; Pfizer, Belgium) and SC-514 (30 $\mu \mathrm{M}$; Sigma-Aldrich Chemical Co.) as required.

\section{Measurement of FKN level in cell culture supernatant}

The level of FKN in the supernatant was determined using enzymelinked immunosorbent assay (ELISA) kits (RayBiotech, Inc., Norcross, GA 30092, USA) according to the manufacturer's instructions.

\section{RNA Isolation and Real-Time PCR analysis of FKN and NF- кB p65 mRNA}

Total RNA of cells was extracted using TRIzol reagent (InVitrogen, USA) according to the manufacturer's instructions. First-strand cDNA was then made from the total RNA using M-MLV reverse transcriptase (C28025, InVitrogen, Shanghai, China) with random primers. The expression levels of FKN and p65 were semiquantitatively measured by real-time PCR using SYBR Green I (204143, Qiagen, Germany) through forced denaturation at $95^{\circ} \mathrm{C}$ for $30 \mathrm{sec}$ and 40 cycles of denaturation at $95^{\circ} \mathrm{C}$ for $10 \mathrm{sec}$, annealing and extension at $65^{\circ} \mathrm{C}$ for $30 \mathrm{sec}$. Primer sequences were designed using the Primer Premier 3.0 program. The optimal reference genes were B2M and HPRT1 in HK-2 cells, determined by geNorm 3.5 software as described previously [28]. Primer sequences (InVitrogen, Shanghai, China) were as follows: FKN forward 5'-CTTGGAGACGAGACAGCACA-3', reverse 5'-ACCACAGACTCGTCCATTCC-3'; p65 forward 5'-CCTGGAGCAGGCTATCAGTC-3', reverse 5'-CACTGTCACCTGGAAGCAGA-3'; B2M forward5'-CCGTGTGAACCATGTGACTT-3', reverse 5'-CCTCCATGATGCTGCTTACA-3'; HPRT1 forward 5'-GGGAGGCCATCACATTGTAG-3', reverse 5'-AATCCAGCAGGTCAGCAAAG-3'. The comparative gene expression was calculated by $2^{-\triangle \triangle \mathrm{Ct}}$ method as described previously [29].

Immunofluorescence staining for the detection of FKN and NF-kB p65 in HK-2 Cells

Immunofluorescence staining of cultured cells was performed as described previously [9]. The cells were incubated with the primary antibodies anti-FKN antibody (ab25088, Abcam Ltd, Hong Kong, 1:200 dilution) or anti-NF- $\mathrm{KB}$ p65 antibody (ab31481, Abcam Ltd, Hong Kong, 1:100 dilution) overnight at $4^{\circ} \mathrm{C}$ and then incubated with secondary antibody Alexa Fluor 488-conjugated goat anti-rabbit IgG (Beyotime Institute of Biotechnology, China, 1:200 dilution) for 60 min at $37^{\circ} \mathrm{C}$. Cells stained with Alexa Fluor 488 conjugates of goat anti-mouse IgG antibody in order to detect HK-2 cells probed with human FKN or NF- $\kappa$ B p65 antibodies. Alexa fluor 488 appeared as green fluorescence and cells nuclei stained with PI appeared as red fluorescence. The image of immunofluorescence staining was scanned by Quantity One software and the original intensity was quantified with freeware image analysis software, NIH Image (National Institute of Health, Bethesda, Md., USA).

\section{Western blot analysis of FKN, NF-кB p65 and phospho p65}

Immunoblot analysis was performed to detect FKN protein, NF$\kappa \mathrm{B}$ p65 protein and phospho p65 in $\mathrm{HK}-2$ cells. Cells were lysed at $4^{\circ} \mathrm{C}$ for $15 \mathrm{~min}$ in lysis buffer (50 mM Tris- $\mathrm{HCl}, \mathrm{pH} 7.4,150 \mathrm{mM} \mathrm{NaCl}, 1 \%$ Triton X-100, 0.1\% SDS, 2 mM EDTA, 0.1 mM EGTA, 5 mM NaF, 1 mM $\mathrm{Na}_{3} \mathrm{VO}_{4}, 5 \mathrm{mM} \mathrm{Na}_{2} \mathrm{PO}_{4}$ and $1 \times$ proteinase inhibitor cocktail (Beyotime Institute of Biotechnology, China)) to a final protein concentration of 2 $\mu \mathrm{g} / \mu \mathrm{L}$. Western blot analysis was conducted and quantified as described by Müller et al. [30]. The following antibodies were used: rabbit antiFKN antibody (ab25088, Abcam Ltd, Hong Kong, 1:100 dilution) or anti-NFkB p65 antibody (ab31481, Abcam Ltd, Hong Kong, 1:200 dilution) or anti-NF- $\mathrm{KB}$ phospho p65 antibody (ab28810, Abcam Ltd, Hong Kong, 1:100 dilution) and mouse anti-beta actin monoclonal antibody (AA128, Beyotime Institute of Biotechnology, China, 1:500 dilution) followed by the goat polyclonal secondary antibody to rabbit IgG-H\&L (HRP) (ab6721, Abcam Ltd, Hong Kong, 1:1000 dilution) or anti-mouse IgG-H+L (A0216, Beyotime Institute of Biotechnology, China, 1:1000 dilution). The image of western blots was scanned by Quantity One software and the original intensity of each specific band was quantified with freeware image analysis software, NIH Image (National Institute of Health, Bethesda, Md., USA).

\section{Statistical analysis}

Data are reported as means \pm SEM for normally distributed data and median (range) for nonparametric data. The comparisons of gene expression levels and demographic characteristics of the participants between groups were performed by using the one-way ANOVA for parametric data, F-test for equality of variances and Newman-Keuls test for heterogeneity of variance. All analyses were conducted with SPSS software, version 18.0. $P$ value $<0.05$ was considered statistically significantly.

\section{Results}

\section{Effect of MP or SC-514 on FKN expression in culture supernatant of LPS-Induced HK-2 cells}

ELISA of FKN expression in culture supernatant of HK-2 cells at 0 , 4,12 and $24 \mathrm{~h}$ is shown in the Figure 1. Compared with control HK-2 cells, the expression of FKN in culture supernatant of LPS-induced HK-2 cells was increased significantly at 4,12 and $24 \mathrm{~h}(P<0.01)$, especially at $24 \mathrm{~h}$. MP or SC-514 attenuated the increased expression of FKN induced by LPS at 4,12 and $24 \mathrm{~h}(P<0.01)$, especially at $24 \mathrm{~h}$. There was no significant change in the expression of FKN between control cells, MP-treated cells and SC-514-treated cells.

\section{Effect of MP or SC-514 on FKN and p65 mRNA Expression in LPS-Induced HK-2 Cells}

Real-time PCR analysis of FKN and 05 mRNA expression in HK-2 cells at $0,4,12$ and $24 \mathrm{~h}$ is shown in Figures 2 and 3. Compared with control HK-2 cells, the expression of FKN mRNA in LPS-induced HK-2 cells was increased significantly at 4,12 and $24 \mathrm{~h}(P<0.01)$, especially at $24 \mathrm{~h}$. MP or SC-514 attenuated the increasing expression of FKN mRNA induced by LPS at 4,12 and $24 \mathrm{~h}(P<0.05)$. Compared with the normal HK- 2 cells, the expression of p 65 mRNA in LPS-induced HK-2 


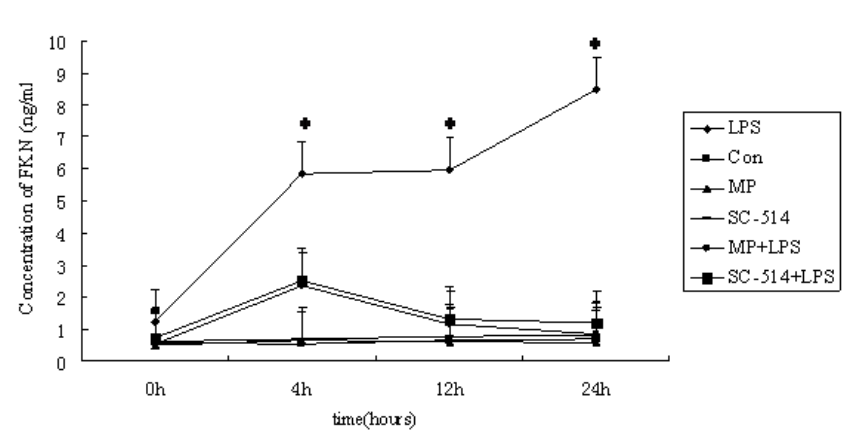

Figure 1: FKN levels in culture supernatant of HK-2 cells at $0,4,12$ and 24 h. Cells were incubated with LPS $(\bullet)$, MP $(\boldsymbol{\Delta})$, SC514 $(*)$, MP+LPS $(\bullet)$ SC-514+MP (घ). *P<0.01 compared to control, MP, SC-514, MP+LPS and SC$514+$ LPS treated cells

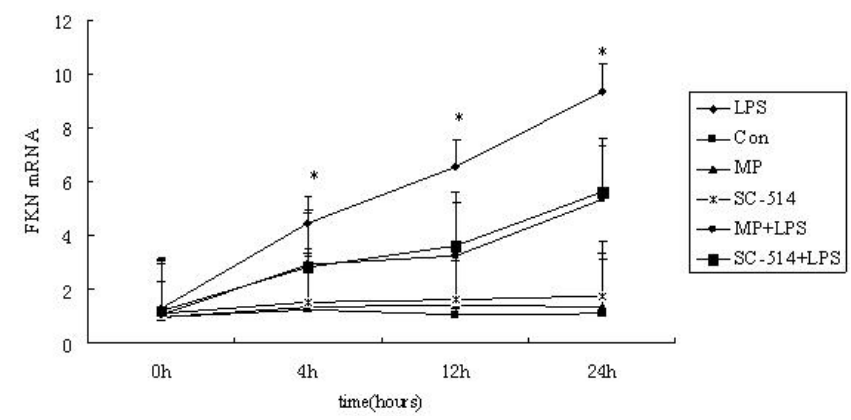

Figure 2: FKN mRNA expression in HK-2 cells at $0,4,12$ and $24 \mathrm{~h}$. Cells were incubated with LPS $(\bullet)$, MP $(\boldsymbol{\Delta}), \operatorname{SC5} 14(*)$, MP+LPS $(\bullet)$, SC-514+MP (ש) ${ }^{*} \mathrm{P}<0.01$ compared to control, MP, SC-514 treated cells, ${ }^{*} \mathrm{P}<0.05$ compared to MP+LPS and SC-514+LPS treated cells.

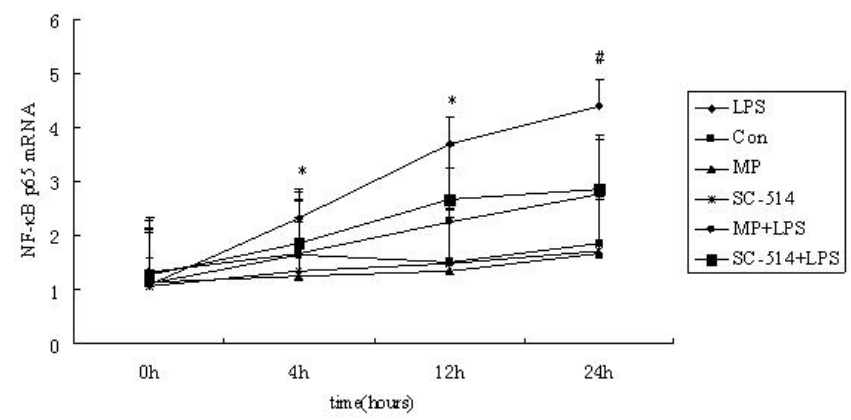

Figure 3: NF-KB p65 mRNA expression in HK-2 cells at 0, 4, 12 and $24 \mathrm{~h}$. Cells were incubated with LPS $(\bullet), \operatorname{MP}(\boldsymbol{\Delta})$, SC514 (*), MP+LPS $(\bullet)$, SC-514+MP (匹). ${ }^{*} \mathrm{P}<0.05$ compared to control, MP and SC-514 treated cells, ${ }^{*} \mathrm{P}<0.01$ compared to MP+LPS and SC-514+LPS treated cells. "P $<0.05$ compared to control, MP, SC-514, MP+LPS and SC-514+LPS treated cells.

cells was increased significantly at 4,12 and $24 \mathrm{~h}(P<0.05)$, especially at $24 \mathrm{~h}$. MP or SC-514 attenuated the increased expression of p65 mRNA induced by LPS at 4,12 and $24 \mathrm{~h}(P<0.01)$. There was no significant change in the expression of FKN between control cells, MP-treated cells and SC-514-treated cells.

\section{Effect of MP or SC-514 on FKN and p65 expression in LPS- Induced HK-2 cells}

Immunofluorescence staining of FKN and p65 expression in HK-2 cells at $24 \mathrm{~h}$ is shown in Figures 4 and 5. Positive staining for FKN and p65 proteins were detected in cytoplasmic and perinuclear regions of HK-2 cells. Compared with control HK-2 cells (78.2 \pm
33.6), the expression of FKN in LPS-induced HK-2 cells was increased significantly at $24 \mathrm{~h}(186.36 \pm 56.25, P<0.01)$. MP or SC-514 attenuated the increasing expression of FKN induced by LPS at $24 \mathrm{~h}(88.7 \pm 38.3$, $81.3 \pm 36.4 ; P<0.05)$. Compared with the normal HK-2 cells $(74.5 \pm$ 29.7), the expression of p65 in LPS-induced HK-2 cells was increased significantly at $24 \mathrm{~h}(156.9 \pm 42.3, P<0.05)$. MP or SC-514 attenuated the increased expression of p65 induced by LPS at $24 \mathrm{~h}(78.6 \pm 25.2$, $77.6 \pm 23.7, P<0.05)$.

\section{Effect of MP or SC-514 on FKN, p65 protein and phospho p65 expression in LPS-Induced HK-2 cells}

Western blot analysis of FKN in HK-2 cells at $24 \mathrm{~h}$ is shown in Figure 6. Compared with the normal HK-2 cells, the expression of FKN protein in LPS-induced HK-2 cells was increased significantly at $24 \mathrm{~h}$ $(P<0.05)$. MP or SC-514 inhibited the increasing expression of FKN protein induced by LPS at $24 \mathrm{~h}(P<0.05)$.

Western blot analysis of p65 protein and phospho p65 in HK-2 cells is shown in Figure 7. Compared with the normal HK-2 cells, the ratio of phospho p65/p65 in LPS-induced HK-2 cells was increased significantly $(P<0.05)$. MP or SC-514 down-regulated the increased ratio of phospho p65/p65 induced by LPS $(P<0.05)$.

\section{Discussion}

Progressive renal interstitial fibrosis is the histological hallmark of chronic renal disease ultimately necessitating renal replacement therapy. Important biological roles of FKN in renal inflammation have been well documented in several tissues including the pancreas [31], joints and arteries [32] and more details are known for tubular and interstitial inflammation [33]. Because FKN has critical roles in renal inflammation, factors affecting its epithelial expression may be important in regulating inflammatory processes in renal interstitial fibrosis.

$\mathrm{NF}-\kappa \mathrm{B}$ is the predominant transcription factor that regulates a wide array of genes that encode pro-inflammatory cytokines, adhesion molecules and chemokines in kidney injury [34,35]. It is now well established that there are large numbers of genes activated via the NF$\kappa \mathrm{B}$ signaling pathway. Activation of NF- $\kappa \mathrm{B}$ could play a central role in inflammatory cytokines-induced FKN expression at the transcriptional level [36]. LPS is a component of gram-negative bacteria that is known to cause pro-inflammatory cytokines production in renal tubular epithelial cells [37]. Previous work revealed that LPS stimulation increases FKN expression through the activation of the NF- $\kappa B$ signaling pathway in vitro [21].

In this study the mechanisms of LPS-induced expression of FKN and the effect of MP on LPS-induced expression of FKN and activation of NF- $\kappa B$ in $\mathrm{HK}-2$ cells were investigated. HK-2 cells were incubated with LPS only or co-incubated with MP or the NF- $\mathrm{BB}$ inhibitor, SC514. The NF- $\kappa B$ expression of FKN and activation of NF- $\kappa B$ were measured. The secretion levels of FKN in cells supernatant was increased significantly after induction by LPS in a dose- and timedependent manner when compared with the control cells. MP and SC514 inhibited LPS-induced FKN secretion. The expression of FKN and p65 mRNA was also detected in gene transcriptional level. Expression of FKN and p 65 mRNA was decreased by MP and SC-514 in HK-2 cells pre-stimulated with LPS.

The expression of FKN and p65 protein in HK-2 cells was detected by immunofluorescence staining and western blotting. HK-2 cells can express FKN and p65 protein. The increased expression of FKN protein in HK-2 cells induced by LPS was accompanied with 
Citation: You YW, Qin YQ, Lin X, Yang FF, Li J, et al. (2015) Inhibition of Lipopolysaccharide-Induced Expression of Fractalkine by Methylprednisolone via NF-Kb in Human Renal Tubular Epithelial Cells. J Pulm Respir Med 5: 249. doi:10.4172/2161-105X.1000249

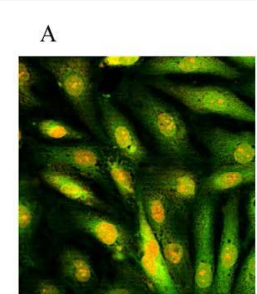

$\mathrm{D}$
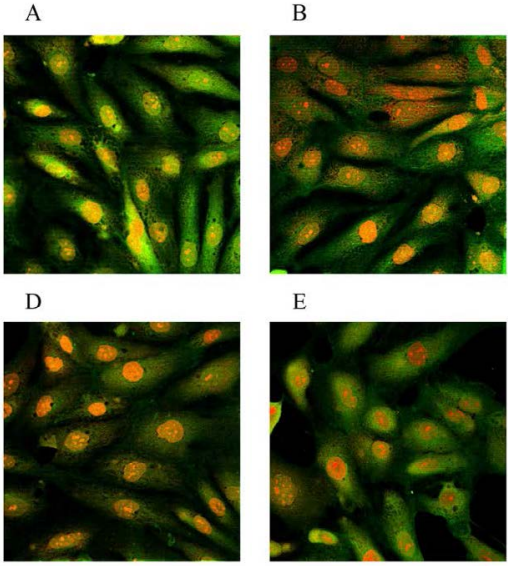

E
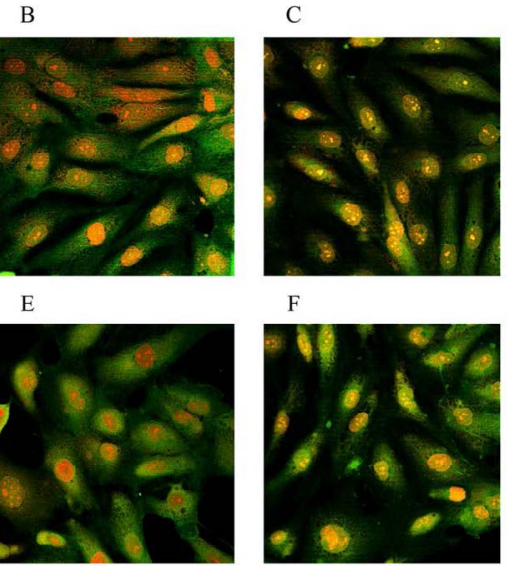

Figure 4: Immunofluorescence staining of FKN expression in HK-2 cells. Magnification $\times 200$. (A) LPS, (B) Control, (C) MP, (D) SC-514, (E) MP+LPS

(F) SC-514+LPS. Alexa fluor 488 appeared as green fluorescence, and $\mathrm{PI}$ appeared as red fluorescence.

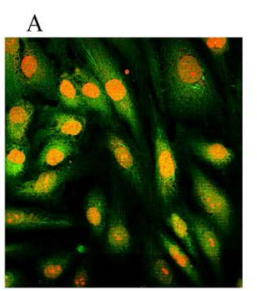

$\mathrm{D}$

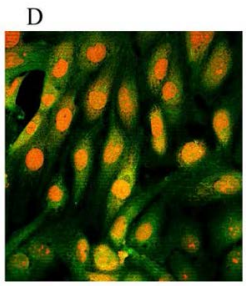

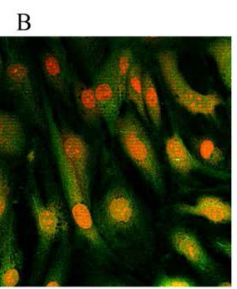

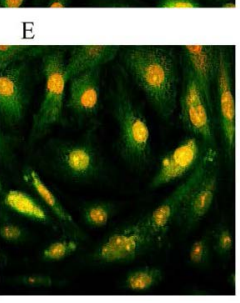

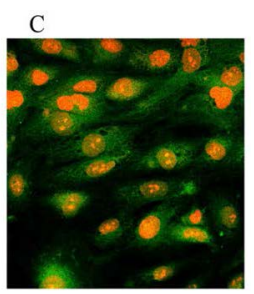

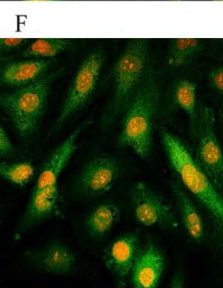

Figure 5: Immunofluorescence staining of p65 expression in HK-2 cells. Magnification $\times 200$. (A) LPS, (B) Control, (C) MP, (D) SC-514, (E) MP+LPS, (F) SC-514+LPS. Alexa fluor 488 appeared as green fluorescence, and PI appeared as red fluorescence.

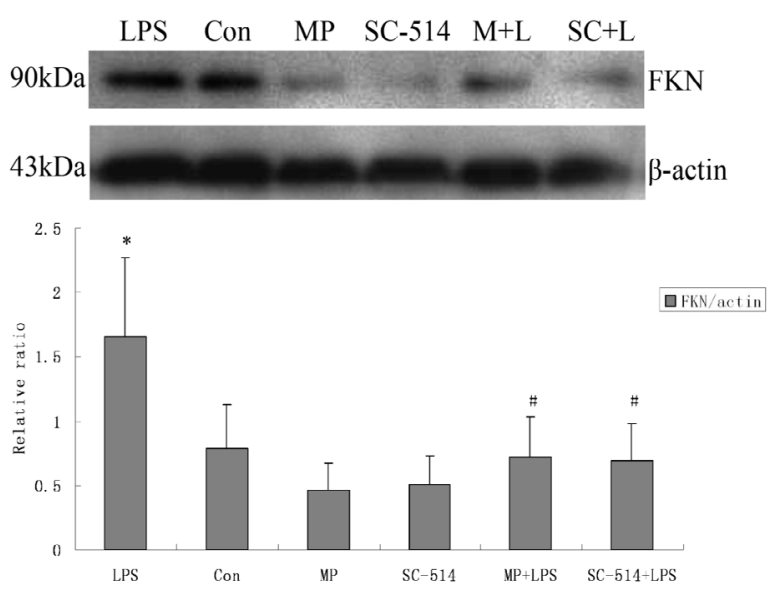

Figure 6: Relative ratio of FKN/actin of HK-2 cells. Cells were incubated with LPS, MP, SC514, MP+LPS, SC-514+LPS. ${ }^{*} \mathrm{P}<0.05$ compared to con, MP and SC-514 treated cells, \#P<0.05 compared to MP+LPS and SC-514+LPS treated cells.

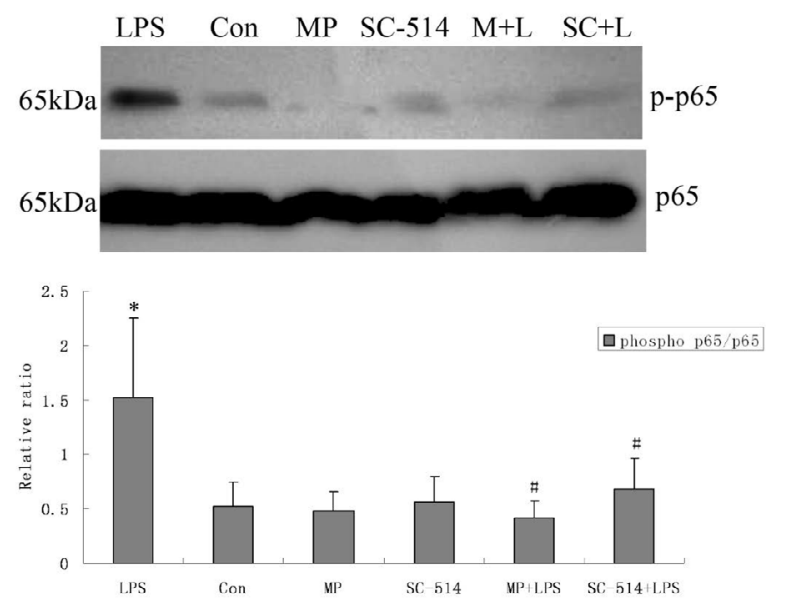

Figure 7: Relative ratio of NF-kB phospho p65/p65 of HK-2 cells. Cells were incubated with LPS, MP, SC514, MP+LPS, SC-514+LPS. *P<0.05 compared to control, MP and SC-514 treated cells, \#P<0.05 compared to MP+LPS and SC-514+LPS treated cells.

increased expression of $\mathrm{p} 65$ protein. The results indicate that MP and SC-514 can inhibit LPS-induced expression of FKN, and p65 mRNA and protein in HK-2 cells.

The activation of NF- $\kappa \mathrm{B}$ by induction with LPS was detected in HK-2 cells. Both MP and SC-514 was able to inhibit the activation of NF- $\kappa B$ induced by LPS. This suggests that the NF- $\kappa B$ signaling pathway was involved in the LPS induced FKN expression in HK-2 cells and that $\mathrm{MP}$ was able to prevent $\mathrm{FKN}$-mediated renal inflammatory injury. The effect of MP was similar to NF- $\mathrm{kB}$ inhibitor, SC-514, suggesting that glucocorticoid MP may inhibit LPS-induced FKN expression via NF$\kappa \mathrm{B}$ pathway.

In summary, LPS induces the expression of FKN and activation of NF- $\kappa \mathrm{B}$ in HK-2 cells. MP inhibits the expression of FKN and $\mathrm{NF}-\kappa \mathrm{B}$ activation induced by LPS in vitro. The inhibition of MP is consistent with NF- $\mathrm{BB}$ inhibitor, SC-514. MP inhibits LPS-induced FKN expression via the NF- B pathway in vitro and this cell culture model may be used to further explore ways of inhibiting inflammation in kidney cells.

\section{Acknowledgements}

This study was supported by grants from the National Natural Science Foundation of China, No. 81160013/H0111, Science and Technique Research Projects of Guangxi, No.1140003B-93 and the Key Programs of Natural Science Foundation of Guangxi, No. 2011GXNSFD018039 as well as Department of Education of Guangxi, Grant No. 201012MS176 and Department of Health of Guangxi, Grant No. 2010058.

\section{References}

1. Anders HJ, Vielhauer V, Schlöndorff D (2003) Chemokines and chemokine receptors are involved in the resolution or progression of renal disease. Kidney Int 63: 401-415.

2. Segerer S, Nelson PJ, Schlöndorff D (2000) Chemokines, chemokine receptors and renal disease: from basic science to pathophysiologic and therapeutic studies. J Am Soc Nephrol 11: 152-176.

3. Koziolek MJ, Vasko R, Bramlage C, Müller GA, Strutz F (2009) The CX(3) C-chemokine fractalkine in kidney diseases. Mini Rev Med Chem 9: 1215-1228.

4. Jones BA, Beamer M, Ahmed S (2010) Fractalkine/CX3CL1: a potential new target for inflammatory diseases. Mol Interv 10: 263-270.

5. Huang LY, Chen P, Xu LX, Zhou YF, Zhang YP, et al. (2012) Fractalkine upregulates inflammation through CX3CR1 and the Jak-Stat pathway in severe acute pancreatitis rat model. Inflammation 35: 1023-1030. 
Citation: You YW, Qin YQ, Lin X, Yang FF, Li J, et al. (2015) Inhibition of Lipopolysaccharide-Induced Expression of Fractalkine by Methylprednisolone via NF-Kb in Human Renal Tubular Epithelial Cells. J Pulm Respir Med 5: 249. doi:10.4172/2161-105X.1000249

6. Koziolek MJ, Müller GA, Zapf A, Patschan D, Schmid H, et al. (2010) Role of $\mathrm{CX} 3 \mathrm{C}$-chemokine CX3C-L/fractalkine expression in a model of slowly progressive renal failure. Nephrol Dial Transplant 25: 684-698.

7. Shimizu K, Furuichi K, Sakai N, Kitagawa K, Matsushima K, et al. (2011) Fractalkine and its receptor, CX3CR1, promote hypertensive interstitial fibrosis in the kidney. Hypertens Res 34: 747-752.

8. Hoffmann U, Bergler T, Segerer S, Rümmele P, Krüger B, et al. (2010) Impac of chemokine receptor CX3CR1 in human renal allograft rejection. Transp Immunol 23: 204-208.

9. Donadelli R, Zanchi C, Morigi M, Buelli S, Batani C, et al. (2003) Protein overload induces fractalkine upregulation in proximal tubular cells through nuclear factor kappaB- and p38 mitogen-activated protein kinase-dependent pathways. J Am Soc Nephrol 14: 2436-2446.

10. Park J, Song KH, Ha H (2012) Fractalkine increases mesangial cell proliferation through reactive oxygen species and mitogen-activated protein kinases. Transplant Proc 44: 1026-1028.

11. Park J, Song KH, Ha H (2012) Lipopolysaccharide increases monocyte binding to mesangial cells through fractalkine and its receptor. Transplant Proc 44: 1029-1031.

12. Chakravorty SJ, Cockwell P, Girdlestone J, Brooks CJ, Savage CO (2002) Fractalkine expression on human renal tubular epithelial cells: potential role in mononuclear cell adhesion. Clin Exp Immunol 129: 150-159.

13. Durkan AM, Alexander RT, Liu GY, Rui M, Femia G, et al. (2007) Expression and targeting of CX3CL1 (fractalkine) in renal tubular epithelial cells. J Am Soc Nephrol 18: 74-83.

14. Katsuyama K, Fujinaka H, Yamamoto K, Nameta M, Yaoita E, et al. (2009) Expression of the chemokine fractalkine (FKN/CX3CL1) by podocytes in normal and proteinuric rat kidney glomerulus. Nephron Exp Nephrol 113: e45-56.

15. Chen YM, Hu-Tsai MI, Lin SL, Tsai TJ, Hsieh BS (2003) Expression of CX3CL1/ fractalkine by mesangial cells in vitro and in acute anti-Thy1 glomerulonephritis in rats. Nephrol Dial Transplant 18: 2505-2514.

16. Iwata Y, Furuichi K, Kaneko S, Wada T (2011) The role of cytokine in the lupus nephritis. J Biomed Biotechnol 2011: 594809.

17. Garton KJ, Gough PJ, Blobel CP, Murphy G, Greaves DR, et al. (2001) Tumor necrosis factor-alpha-converting enzyme (ADAM17) mediates the cleavage and shedding of fractalkine (CX3CL1). J Biol Chem 276: 37993-38001.

18. Yu MH, Choi JH, Chae IG, Im HG, Yang SA, et al. (2013) Suppression of LPSinduced inflammatory activities by Rosmarinus officinalis L. Food Chem 136: 1047-1054.

19. Wang WM, Chen H, Zhong F, Lu Y, Han L, et al. (2011) Inhibitory effects of rosiglitazone on lipopolysaccharide-induced inflammation in a murine mode and HK-2 cells. Am J Nephrol 34: 152-162.

20. Hu F, Liang W, Ren Z, Wang G, Ding G (2012) Surfactant protein D inhibits lipopolysaccharide-induced monocyte chemoattractant protein-1 expression in human renal tubular epithelial cells: implication for tubulointerstitial fibrosis. Clin Exp Immunol 167: 514-522.
21. Sung MJ, Kim W, Ahn SY, Cho CH, Koh GY, et al. (2005) Protective effect of alpha-lipoic acid in lipopolysaccharide-induced endothelial fractalkine expression. Circ Res 97: 880-890

22. Beinke S, Ley SC (2004) Functions of NF-kappaB1 and NF-kappaB2 in immune cell biology. Biochem J 382: 393-409.

23. Chen YY, Chiang SY, Wu HC, Kao ST, Hsiang CY, et al. (2010) Microarray analysis reveals the inhibition of nuclear factor-kappa $B$ signaling by aristolochic acid in normal human kidney (HK-2) cells. Acta Pharmacol Sin 31: 227-236.

24. Rogler G (2006) Significance of anti-inflammatory effects of PPARgamma agonists? Gut 55: 1067-1069.

25. Chandrasekar B, Mummidi S, Perla RP, Bysani S, Dulin NO, et al. (2003) Fractalkine (CX3CL1) stimulated by nuclear factor kappaB (NF-kappaB)dependent inflammatory signals induces aortic smooth muscle cell proliferation through an autocrine pathway. Biochem J 373: 547-558.

26. Garcia GE, Xia Y, Chen S, Wang Y, Ye RD, et al. (2000) NF-kappaB-dependent fractalkine induction in rat aortic endothelial cells stimulated by IL-1beta, TNFalpha, and LPS. J Leukoc Biol 67: 577-584.

27. Bhavsar PK, Sukkar MB, Khorasani N, Lee KY, Chung KF (2008) Glucocorticoid suppression of $\mathrm{CX} 3 \mathrm{CL} 1$ (fractalkine) by reduced gene promoter recruitment of NF-kappaB. FASEB J 22: 1807-1816.

28. Pinhu L, Park JE, Yao W, Griffiths MJ (2008) Reference gene selection fo real-time polymerase chain reaction in human lung cells subjected to cyclic mechanical strain. Respirology 13: 990-999.

29. Schmittgen TD, Livak KJ (2008) Analyzing real-time PCR data by the comparative $\mathrm{C}(\mathrm{T})$ method. Nat Protoc 3: 1101-1108.

30. Müller HK, Wegener G, Popoli M, Elfving B (2011) Differential expression of synaptic proteins after chronic restraint stress in rat prefrontal cortex and hippocampus. Brain Res 1385: 26-37.

31. Huang L, Ma J, Tang Y, Chen P, Zhang S, et al. (2012) siRNA-based targeting of fractalkine overexpression suppresses inflammation development in a severe acute pancreatitis rat model. Int J Mol Med 30: 514-520.

32. Clark AK, Staniland AA, Malcangio M (2011) Fractalkine/CX3CR1 signalling in chronic pain and inflammation. Curr Pharm Biotechnol 12: 1707-1714.

33. Cockwell P, Chakravorty SJ, Girdlestone J, Savage CO (2002) Fractalkine expression in human renal inflammation. J Pathol 196: 85-90.

34. Sanz AB, Sanchez-Niño MD, Ramos AM, Moreno JA, Santamaria B, et al. (2010) NF-kappaB in renal inflammation. J Am Soc Nephrol 21: 1254-1262.

35. Rangan G, Wang Y, Harris D (2009) NF-kappaB signalling in chronic kidney disease. Front Biosci (Landmark Ed) 14: 3496-3522.

36. Ahn SY, Cho CH, Park KG, Lee HJ, Lee S, et al. (2004) Tumor necrosis factoralpha induces fractalkine expression preferentially in arterial endothelial cells and mithramycin A suppresses TNF-alpha-induced fractalkine expression. Am J Pathol 164: 1663-1672

37. Wang Y, Rangan GK, Goodwin B, Tay YC, Harris DC (2000) Lipopolysaccharideinduced MCP-1 gene expression in rat tubular epithelial cells is nuclear factorkappaB dependent. Kidney Int 57: 2011-2022. 